\title{
Cytokine Patterns in the Pathogenesis of Human Leishmaniasis
}

\author{
Claude Pirmez, * Masahiro Yamamura, " Koichi Uyemura, " Manoel Paes-Oliveira," Fátima Conceição-Silva," \\ and Robert L. Modlin* \\ * Department of Biochemistry and Molecular Biology, "Department of Protozoology, and ${ }^{\S}$ Evandro Chagas Hospital, Fundação Oswaldo \\ Cruz, Rio de Janeiro, Brazil; and ${ }^{\ddagger}$ Division of Dermatology and Department of Microbiology and Immunology, UCLA School of \\ Medicine, Los Angeles, California 90024
}

\begin{abstract}
The host response to infection appears to be regulated by specific patterns of local cytokine production. In the mouse, resistance to many pathogens including Leishmania is associated with a $T_{H} 1$ cytokine profile, IL-2 and IFN- $\gamma$; whereas susceptibility to infection is associated with production of $\mathbf{T}_{\mathrm{H}} 2$ cytokines, IL-4, IL-5, and IL-10. To determine the cytokine patterns of the local immune response to Leishmania infection in humans, we used the polymerase chain reaction to compare cytokine mRNAs in biopsy specimens of American cutaneous leishmaniasis. In localized cutaneous leishmaniasis and the Montenegro delayed-type hypersensitivity reaction, type 1 cytokine mRNAs such as IL-2, IFN- $\gamma$, and lymphotoxin were relatively predominant. In the chronic and destructive mucocutaneous form of leishmaniasis, there was a mixture of type 1 and type 2 cytokines, with a striking abundance of IL-4 mRNA in lesions. These results suggest that clinical course of infection with Leishmania braziliensis in man is associated with specific local patterns of cytokine production. (J. Clin. Invest. 1993. 91:1390-1395.) Key words: cytokines • interleukin 4 - leishmaniasis $\bullet$ polymerase chain reaction $\bullet T$ lymphocytes
\end{abstract}

\section{Introduction}

The human immune response to infectious pathogens usually results in limited disease with spontaneous resolution of the primary focus. However, in some instances, the infection can recur or progress as a more chronic form. This scenario is exemplified in the human response to the parasite Leishmania braziliensis. The most common clinical form of disease caused by L. braziliensis is localized cutaneous leishmaniasis (LCL), characterized by single or multiple ulcerated dermal lesions that usually heal spontaneously. However, in $2-5 \%$ of LCL patients in Brazil, a chronic mucocutaneous (MCL) form arises in which there is severe and progressive destruction of the nasal, oral, and/or pharyngeal mucous membranes.

Address reprint requests to Dr. Robert L. Modlin, Div. of Dermatology, 52-121 CHS, UCLA School of Medicine, 10833 Le Conte Avenue, Los Angeles, CA 90024.

Received for publication 5 June 1992 and in revised form 14 September 1992.

1. Abbreviations used in this paper: $\mathrm{ACL}$, American cutaneous leishmaniasis; LCL, localized cutaneous leishmaniasis; MCL, mucocutaneous leishmaniasis.

J. Clin. Invest.

(C) The American Society for Clinical Investigation, Inc.

$0021-9738 / 93 / 04 / 1390 / 06 \$ 2.00$

Volume 91, April 1993, 1390-1395
Although T cells are believed to contribute to the pathogenesis of the different forms of American cutaneous leishmaniasis (ACL), it has not been determined whether there are any differences in the T cell response in LCL vs. MCL patients. Resolution of LCL lesions is associated with acquisition of a specific cell-mediated immune response (1-3). For example, the Montenegro skin test, a 48-h delayed-type hypersensitivity reaction to intradermal challenge with Leishmania antigen, is positive in LCL patients $(4,5)$. However, the test is even more positive in MCL patients. Peripheral blood T cell responses to Leishmania antigen are of significant magnitude in both $\mathrm{LCL}$ and MCL patients. Furthermore, immunopathologic examination of skin lesions from both LCL and MCL patients showed remarkably similar $\mathrm{T}$ cell patterns (6).

The present study was undertaken to determine the range of cytokines produced in human lesions of ACL. To perform a comprehensive analysis of multiple cytokines expressed in these small biopsy specimens, we exploited the power of PCR using cytokine-specific oligonucleotide primers.

\section{Methods}

Patients. Biopsy specimens were obtained from 10 patients with LCL and 10 patients with MCL. Although some patients with MCL had cutaneous lesions, all biopsy specimens studied were taken from mucosal lesions. All MCL specimens were from the nasal mucosa and were of uniform size and histology. The diagnosis was established by means of clinical, epidemiologic, parasitologic (imprints, cultivation either in Schneider's or NNN make and histologic exam), and/or immunologic parameters (Montenegro skin test and indirect immunofluorescence analysis) criteria. Montenegro skin tests were performed by injecting $0.1 \mathrm{ml}$ of leishmanin $(40 \mu \mathrm{g}$ nitrogen $/ \mathrm{ml}$ ) intradermally, and measuring induration after $48 \mathrm{~h}$. Induration $<5 \mathrm{~mm}$ in diameter was considered to be a positive response. Development of cutaneous lesions required an average of $3 \mathrm{mo}$ and all were ulcerated. All cases were from an endemic area of Rio de Janeiro, Brazil, where only L. braziliensis has been isolated (7). In addition, four Montenegro skin tests were studied from patients with cutaneous lesions. The clinical data of the patients studied is included in Table I.

Biopsy specimens. Incisional skin biopsy specimens from the border of the ulcer of LCL lesions, incisional biopsy specimens from MCL lesions, and punch biopsies from positive Montenegro skin tests were obtained, embedded in OCT medium (Ames Co., Elkhart, IN) and rapidly frozen in liquid nitrogen. The tissues were stored at $-70^{\circ} \mathrm{C}$ until sectioning.

$R N A$ isolation and cDNA synthesis. Total RNA was isolated from biopsy specimens by the method of Chomczynski and Sacchi (8). To facilitate the rapid lysis of the cells isolated from tissue, $40 \times 5 \mu \mathrm{m}$ cryostate sections were added to $4 \mathrm{M}$ guanidinium isothiocyanate buffer. The samples were treated with DNase 1 (Promega Corp., Madison, WI) for $30 \mathrm{~min}$ at $37^{\circ} \mathrm{C}$. RNase inhibitor (Boehringer Mannheim Corp., Indianapolis, IN) was present during all enzymatic manipulations of RNA. cDNA was synthesized from oligo-dT primed RNA by incubation at $42^{\circ} \mathrm{C}$ with AMV reverse transcriptase (Bethesda Research Laboratories, Gaithersburg, MD) and $0.5 \mathrm{mM}$ dNTPs for $1 \mathrm{~h}$. 
Table I. Clinical Features of Patients with Leishmaniasis

\begin{tabular}{|c|c|c|c|c|c|c|c|}
\hline Case & Age & Sex & Duration & Location & $\begin{array}{l}\text { No. of } \\
\text { skin } \\
\text { lesions }\end{array}$ & $\begin{array}{l}\text { Parasite } \\
\text { isolation }\end{array}$ & MTN \\
\hline & & & & & & & $m m$ \\
\hline LCL 1 & 61 & $\mathbf{M}$ & $8 \mathrm{mo}$ & leg & 1 & neg & 18 \\
\hline LCL 2, 3* & 22 & $\mathbf{M}$ & $9 \mathrm{mo}$ & leg & 2 & neg & 26 \\
\hline LCL 4 & 23 & $\mathbf{M}$ & $2 \mathrm{mo}$ & face & 1 & pos & 16 \\
\hline LCL 5 & 12 & $\mathbf{M}$ & $3 \mathrm{mo}$ & face & 3 & pos & 25 \\
\hline LCL 6 & 34 & $\mathrm{~F}$ & $3 \mathrm{mo}$ & arm & 3 & pos & 38 \\
\hline LCL 7 & 32 & $\mathrm{~F}$ & $7 \mathrm{mo}$ & leg & 2 & pos & 66 \\
\hline LCL 8 & 70 & $F$ & $3 \mathrm{mo}$ & arm & 2 & pos & 28 \\
\hline LCL 9 & 10 & $\mathbf{F}$ & $1 \mathrm{mo}$ & arm & 1 & pos & 40 \\
\hline LCL 10 & 14 & $\mathrm{~F}$ & $3 \mathrm{mo}$ & leg & 1 & neg & 26 \\
\hline LCL 11 & 17 & $F$ & $3 \mathrm{mo}$ & gluteal & 1 & pos & 30 \\
\hline MCL 1 & 49 & $\mathbf{M}$ & $7 \mathrm{mo}$ & nasal & 0 & pos & 40 \\
\hline MCL 2 & 23 & $\mathbf{M}$ & $3 \mathrm{mo}$ & nasal & 0 & neg & 80 \\
\hline MCL 3 & 78 & $\mathbf{M}$ & $8 \mathrm{yr}$ & nasal + pharyngeal & 0 & neg & 45 \\
\hline MCL 4 & 76 & $\mathbf{M}$ & $1 \mathrm{yr}$ & nasal & 0 & neg & 40 \\
\hline MCL 5 & 79 & $\mathbf{M}$ & $6 \mathrm{yr}$ & nasal & 0 & pos & 30 \\
\hline MCL 6 & 34 & $\mathbf{F}$ & $3 \mathrm{mo}$ & nasal + oral & 4 & pos & 28 \\
\hline MCL 7 & 35 & $\mathbf{M}$ & $2 \mathrm{yr}$ & nasal + pharyngeal & 6 & neg & 74 \\
\hline MCL 8 & 18 & $\mathrm{~F}$ & $2 \mathrm{mo}$ & nasal & 5 & pos & 48 \\
\hline MCL 9 & 34 & $\mathbf{M}$ & $4 \mathrm{yr}$ & nasal + oral & 0 & pos & 40 \\
\hline MCL 10 & 20 & $\mathbf{M}$ & $20 \mathrm{yr}$ & nasal + oral & 0 & neg & 50 \\
\hline MTN 1 & 19 & $\mathbf{M}$ & $2 \mathrm{mo}$ & leg & 3 & pos & 26 \\
\hline MTN 2 & 24 & $\mathbf{M}$ & $3 \mathrm{mo}$ & leg & 1 & neg & 34 \\
\hline MTN 3 & 30 & $\mathbf{M}$ & $3 \mathrm{mo}$ & forearm & 1 & neg & 18 \\
\hline MTN 4 & 34 & $\mathbf{F}$ & $3 \mathrm{mo}$ & leg & 1 & pos & 8 \\
\hline
\end{tabular}

* Two specimens were obtained from the same patient and were labeled LCL 2 and LCL 3. Montenegro (MTN) tests were obtained from LCL patients. Some MCL patients had cutaneous lesions, but only mucosal (nasal mucosa) lesions were obtained for this study.

PCR. PCR was performed as previously described (9). Briefly, the PCR reaction mixture contained PCR buffer (Promega Corp.) supplemented with $2.5 \mathrm{mM} \mathrm{MgCl}_{2}, 0.2 \mathrm{mM}$ dNTP, $25 \mathrm{pM}$ 5' and 3' oligonucleotide primers, and $2.5 \mathrm{U}$ Taq polymerase (Promega Corp.). Samples were then amplified in a DNA Thermocycler (Perkin-Elmer Corp., Norwalk, CT) for 35 or 40 cycles. Each cycle consisted of denaturation at $94^{\circ} \mathrm{C}$ for $1 \mathrm{~min}$ and annealing/extension at $55^{\circ} \mathrm{C}$ (for IL-2 and IFN- $\gamma$ ) or $65^{\circ} \mathrm{C}$ for 2 min (all other cytokines). An aliquot of PCR product was then electrophoresed on $2 \%$ agarose gels and visualized by ethidium bromide staining. The sequences of cytokine-specific primer pairs, $5^{\prime}$ and $3^{\prime}$, are as follows:

$\beta$-Actin:GTGGGGCGCCCCAGGCACCAandCTCCTTAATGTCACGCACGATTTC;

IL-1 $\beta$ : GACACATGGGATAACGAGGC and ACGCAGGACAGGTACAGATT;

IL-2: ACTCACCAGGATGCTCACAT and AGGTAATCCATCTGTTCAGA;

IL-4:CTTCCCCCTCTGTTCTTCCT and TTCCTGTCGAGCCGTTTCAG;

IL-5: ATGAGGATGCTTCTGCATTTG and TCAACTTTCTATTATCCACTCGGTGTTCATTAC;

IL-6: ATGTAGCCGCCCCACACAGA and CATCCATCTTTTTCAGCCAT;

IL-10: ATGCCCCAAGCTGAGAACCAAGACCCA and TCTCAAGGGGCTGGGTCAGCTATC-CCA;

IFN- $\gamma$ : AGTTATATCTTGGCTTTTCA and ACCGAATAATTAGTCAGCTT;
TNF- $\alpha$ : TCTCGAACCCCGAGTGACAA and TATCTCTCAGCTCCACACCA;

LT:CCTCACACCTTCAGCTGCCCandGAGAAACCATCCTGGAGGAA;

GM-CSF:TGGCTGCAGAGCCTGCTGCTC and TCACTCCTGGACTGGCTCCC;

CD3 $\delta$ : CTGGACCTGGGAAAACGCATC and GTACTGAGCATCATCTCGATC.

Radioactive hybridization of PCR product. To verify cytokine mRNAs, PCR products were transferred to Hybond-N nylon membranes (Amersham Corp., Arlington Heights, IL) and probed with a labeled oligonucleotide complementary to sequences internal to the sequences recognized by the PCR amplification primers. Blots were hybridized for $4 \mathrm{~h}$, washed for $5 \mathrm{~min}$ with $2 \times$ SSC and $0.1 \%$ SDS, followed by $0.2 \times$ SSC and $0.5 \%$ SDS at ambient temperature, and exposed to X-ray film. Sequences of the oligonucleotide probes were: IL-2: AGCTAAATTTAGCACTTCCTCCAG;

IL-4: CTCGGTGCTCAGAGTCTTCTGCTCT;

IL-5: GCCAATGAGACTCTGAGGATTCCTG;

IL-10: CAGGTGAAGAATGCCTTTAATAAGCTCCAACAGAAAGGCATCTACAAAGCCATGAGTGACTTTGACATC;

IFN- $\gamma$ : ATTTGGCTCTGCATTATTTTTCTGT;

LT: TCTGCTTGCTGGGGTCTCCAATGAG.

Quantification of PCR product. PCR products were quantified using an AMBIS radioanalytic imaging system (Automated Microbiology Systems Inc., San Diego, CA). Gels were scanned and the amount of radioactivity hybridized to specific PCR products was determined. 
The intensity of individual bands was expressed as "relative cpm" with the most intense band assigned the value of 100 and the other bands expressed as a percentage. Statistical differences between groups were assessed by the Student $t$ test on actual cpm.

Validity of PCR. PCR analysis of 10 -fold serially diluted plasmids containing IL-2, IL-4, IFN- $\gamma$, IL-6, IL-10, and TNF- $\alpha$ cDNAs indicated by visualization by ethidium bromide staining that our PCR procedure was sensitive to the order of $10^{2}$ to $10^{3}$ copies for each cytokine (10). Furthermore, the intensity of the PCR product increased according to the number of copies of starting plasmid to at least $10^{9}$ copies. These PCR products were transferred to nylon membrane, probed, and quantified by radioanalytic imaging. There was a log-linear correlation between the number of starting copies and the quantity of PCR products throughout the range investigated. These results indicate that our PCR conditions provide meaningful comparison of the small amounts of cytokine mRNAs present in lesions.

A number of controls were employed to ensure accurate comparisons of the different samples studied. Upon PCR amplification of serial 10-fold dilutions of sample cDNAs a concomitant decrease in the PCR product was observed. Similarly, varying the number of PCR cycles did not change the relative differences between samples. These studies indicate that our PCR conditions are not within the plateau phase of amplification. Mixing of cDNAs from different patients did not inhibit or augment PCR amplification, indicating that cDNAs do not directly alter PCR efficiency. Each experiment included a positive control (PMA + ionomycin-treated PBMC) and a negative control ( either sample RNA that had not been reverse transcribed or buffer alone). The latter control did not yield PCR product confirming the absence of extraneous CDNA or PCR product contaminating the samples. In addition, we routinely used extensive precautions to avoid PCR artifact including assembling reactions in laminar flow hoods, use of aliquoted reagents, pipettes dedicated for assembling PCR reactions, and aerosolresistant tips (Continental Lab Products, La Jolla, CA).

\section{Results}

Cytokine patterns in leishmaniasis lesions determined by PCR. Several cytokines are produced by a variety of cell types including lymphocytes, macrophages, and keratinocytes. To ascertain whether the pattern of these cytokines in lesions could be correlated with the clinical expressions of ACL, we examined cytokine expression in ACL lesions by PCR. Initially, cDNAs were normalized to the $\beta$-actin PCR product to standardize the amount of PCR total cellular mRNA in each PCR reaction. We compared the cytokine patterns for LCL and MCL lesions to that of Montenegro reactions, the standard measure of delayed-type hypersensitivity in this disease (Fig. 1). IL-1 $\beta$ and TNF- $\alpha$ mRNAs were strongly expressed in virtually all biopsy specimens studied, with little discernible difference between the various disease states. IL-6 and GM-CSF mRNAs were strongly expressed in approximately one half of the specimens, again with little difference between each disease state. We conclude from these experiments that this set of cytokines, largely produced by macrophages, is equally expressed in LCL and MCL lesions, as well as Montenegro reactions.

To compare lymphokine mRNAs in leishmaniasis lesions, cDNAs from different samples and disease states were normalized to the CD3 $\delta$ PCR product as a control for quantity of $T$ cell mRNA template for amplification. The amount of cDNA used was identical to that according to $\beta$-actin normalization in $90 \%$ of specimens. Examination of electrophoresed PCR product indicated distinct lymphokine patterns in the different disease states (Fig. 2). IL-2 (although weakly expressed), IFN- $\gamma$, and lymphotoxin mRNAs were again present in LCL, MCL,
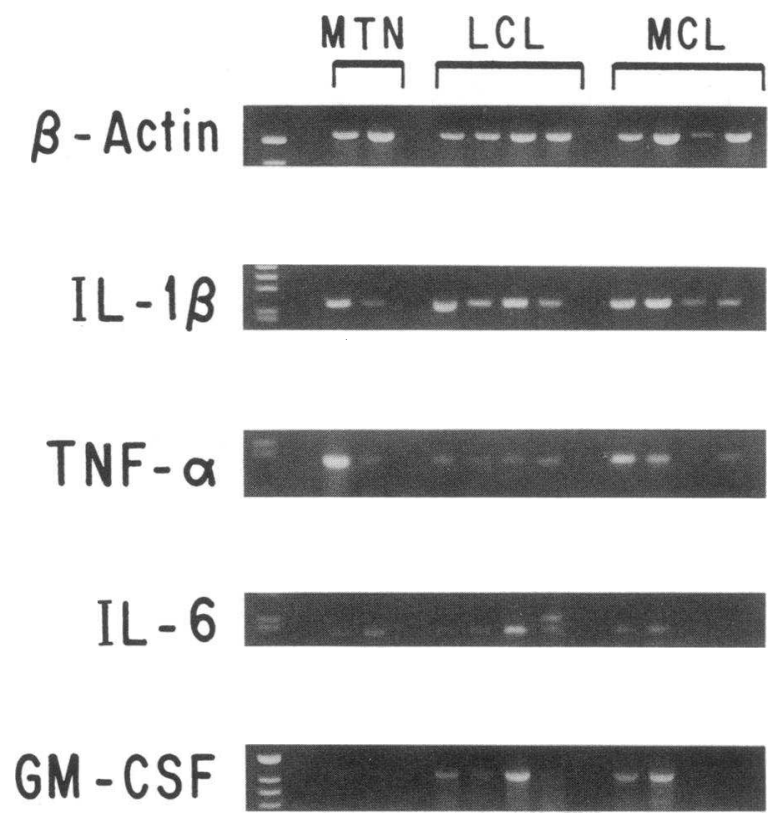

Figure 1. PCR amplification of cytokine mRNAs associated with a variety of cell types. RNA was isolated from lesions, and cDNA was synthesized and normalized to the amount of $\beta$-actin PCR product. PCR was performed using specific paired oligonucleotide primers. The results are shown for a representative sample of all patients studied. MTN, Montenegro reaction.

and Montenegro reactions. In marked contrast, however, the levels of IL-4, IL-5, and IL-10 mRNAs were, in general, higher in MCL lesions. IL-4 PCR product was prominent in three of six MCL specimens, with moderate PCR product detected in an additional two of six biopsies. These results were confirmed by Southern blot analysis of the PCR products. In contrast, significant IL-4 PCR product could be derived from only one of six LCL specimens. These results indicate that the pattern of lymphokine mRNAs in MCL lesions was distinct from LCL and Montenegro reactions. The cytokine mRNA levels measured by PCR were much greater than that found in normal skin (Uyemura et al., manuscript submitted for publication).

Quantification of lymphokine $\mathrm{mRNAs}$ in leishmaniasis lesions. To more accurately compare the levels of lymphokine mRNAs in lesions, PCR products were transferred to nylon membrane, hybridized with a ${ }^{32} \mathrm{P}$-labeled oligonucleotide primer complementary to a sequence internal to the PCR amplification primers, and scanned according to $\beta$ emission. The levels of PCR products for IL-2, IFN- $\gamma$, and lymphotoxin were similar for all the forms of ACL studied (Fig. 3, top left). In each instance the level of PCR product was greater, although not significantly, in LCL compared to MCL lesions.

The most striking finding of the present study was that the levels of IL-4 mRNA as determined by PCR were elevated in MCL lesions compared to LCL lesions $(P<0.001)$ and Montenegro reactions (Fig. 3, top left and bottom). These results indicate a potentially important role for IL-4 in the pathogenesis of MCL. Titration of plasmid containing IL-4 cDNA (10) indicated that the three- to fourfold differences in relative cpm represent $\sim 1,000$-fold differences in sample cDNA. The IL-5 and IL-10 PCR products appeared to be greater in MCL than LCL lesions but these differences did not achieve statistical significance. 

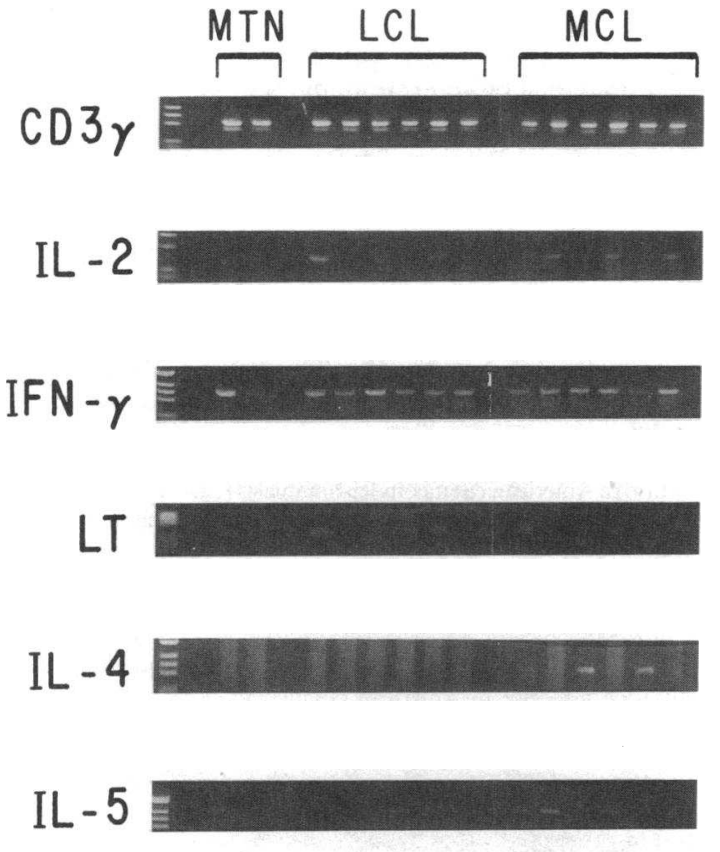

$$
\text { IL }-10
$$

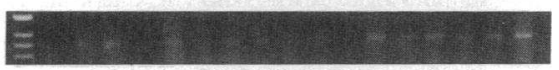

Figure 2. PCR amplification of cytokine mRNAs predominantly associated with $T$ cells. The cDNAs were normalized to the amount of the CD3 $\delta$ PCR product. Although IL-2, IFN- $\gamma$, and lymphotoxin mRNAs are expressed at equivalent levels in all the forms of leishmaniasis studied, IL-4 and, to a lesser extent IL-5 and IL-10 mRNAs, were most abundant in MCL lesions. MTN, Montenegro reaction.

\section{Discussion}

The identification of the cytokines that are involved in resistance to infection and/or contribute to tissue injury has been advanced by the study of disease in murine models. These investigations have identified two immunoregulatory subsets of murine CD4-positive cells that influence the outcome of infection (11). T cells that produce IL-2 and IFN- $\gamma$, termed $T_{H} 1$ cells (11), augment cell-mediated immune responses by activating macrophages to kill or inhibit the growth of the pathogen. The $T_{H} 1$ response results in mild or self-curing disease. In contrast, $T$ cells producing IL-4, IL-5, and IL-10, termed $\mathrm{T}_{\mathrm{H}} 2$ cells, augment humoral responses and inhibit some cell-mediated immune responses, which results in disseminated infection. These patterns have been shown to correlate with the outcome of Leishmania infection in murine models, with resistance versus susceptibility regulated by $T_{H} 1$ and $T_{H} 2$ populations, respectively (12-16).

It is not at all clear whether similar patterns of cytokine production correlate with the human manifestations of Leishmania infection. In our previous study of ACL lesions in Brazil, we found that: (a) CD4-positive T memory cells were the predominant phenotype in both $\mathrm{LCL}$ and MCL lesions as well as Montenegro reactions; $(b)$ IFN- $\gamma$ mRNA-containing cells were present in similar frequencies in LCL, MCL, and Montenegro biopsy specimens; and (c) T-cells derived from both LCL and MCL lesions proliferated equally well to $L$. braziliensis in vitro (6). To explore more fully the patterns of cytokine expression in ACL lesions, we used PCR to amplify cytokine
mRNAs. The key finding of the present study was that mRNAs for IL-4, and to a lesser extent IL-5 and IL-10, were most abundant in MCL lesions. Other cytokines studied, such as TNF- $\alpha$, IL-1 $\beta$, IL-6, GM-CSF, IL-2, IFN- $\gamma$, and lymphotoxin appear equally abundant in LCL and MCL lesions as well as Montenegro reactions. Analysis of a larger group of patients should more fully define the cytokine pattern associated with each form of the disease.

Specific lymphokine patterns have recently been found to be associated with the response to infection in humans. In normal individuals and individuals with resistance to mycobacterial infection, the "type 1" lymphokine pattern, typified by IL-2 and IFN- $\gamma$, is selected for by peripheral blood T cells in response to mycobacteria $(17,18)$. Type 1 lymphokines and lymphokine mRNAs predominate in the lesions of patients with limited infection to Mycobacterium leprae, termed tuberculoid leprosy $(9,19,20)$. In contrast, "type 2" lymphokine mRNAs, such as IL-4, IL-5, and IL-10, predominate in the lesions of lepromatous leprosy patients, individuals with susceptibility to widespread infection (9). Type 2 lymphokines also appear to be associated with Loa loa infection in humans $(21,22)$. Distinct functional populations of human $\mathrm{T}$ cells conforming to these specific cytokine patterns have also been elucidated. CD4-positive clones from tuberculoid leprosy lesions produce IFN- $\gamma$ and CD8-positive $\mathrm{T}$ suppressor clones from lepromatous leprosy lesions are responsible for IL-4 production (23). In the present study, LCL lesions as well as the Montenegro DTH reaction appear to typify the type 1 response, characteristic of limited and/or self-healing lesions. The type 1 pattern was also found in the Montenegro reaction,
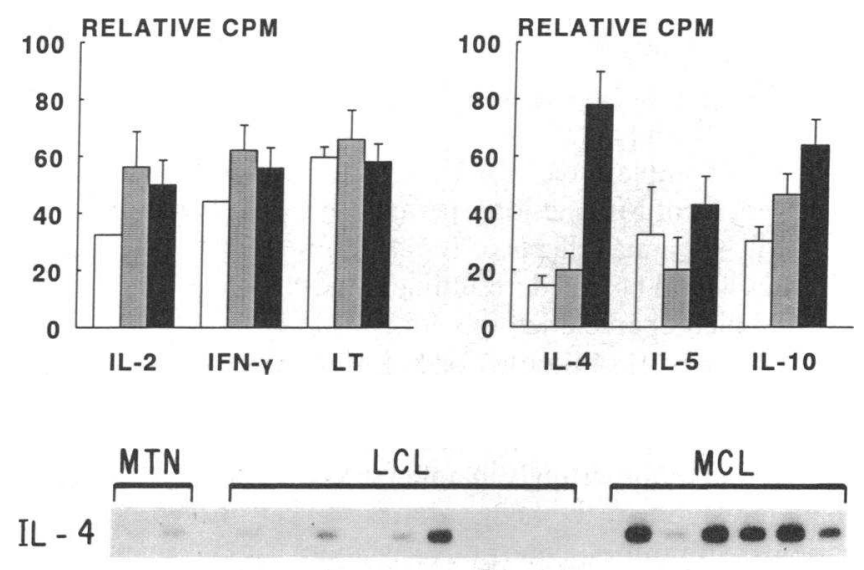

Figure 3. Quantification of lymphokine PCR products in leishmaniasis lesions. The cDNAs derived from lesions were normalized to CD3 $\delta$. The products were electrophoresed, transferred to nylon membranes, and hybridized with a radiolabeled internal oligonucleotide probe. The transfers were then scanned with an automated $\beta$ scanner. The intensity of individual bands was expressed as "relative cpm" with the most intense band assigned a value of 100 and the other bands expressed as a percentage. Data are shown for three Montenegro reactions ( $\square$ ), nine LCL ( $\square$ ), and nine MCL ( $\square$ ) specimens. Data is expressed as mean \pm SEM. Top left: Quantification of type 1 lymphokines in lesions: IL-2, IFN- $\gamma$, and lymphotoxin. Top right: Quantification of type 2 lymphokines in lesions: IL-4, IL-5, and IL-10. Bottom: Hybridization of IL-4 PCR products from human leishmaniasis lesions. Cases shown from left to right according to lane are as follows: Montenegro reaction (MTN), lanes 1 and 2; LCL, lanes 1-9; and MCL, lanes 1-6. 
a typical delayed-type hypersensitivity response. The abundance of IL-2, IFN- $\gamma$, and lymphotoxin is likely to contribute to the resistant state of immunity and elimination of parasites. IFN- $\gamma$ is well known to enhance production of reactive oxygen and nitrogen intermediates (24) and facilitate the intracellular killing of Leishmania (25-27). The progression of the disease in BALB/c mice infected with L. major is associated with an inability of the animals to produce IFN- $\gamma(28)$.

On the other hand, MCL lesions appear to be characterized by a mixture of type 1 and type 2 lymphokines. The greatest difference found in MCL versus LCL lesions was the several orders of magnitude greater amount of IL-4 mRNA in MCL lesions. The anatomic site of MCL, the mucosa, may be a predisposing factor to enhanced IL-4 production and may contribute to the pathogenesis of this form of the disease. It has been shown that $\mathrm{T}$-cells in lymphoid organs draining nonmucosal tissue sites produce IL-2 whereas those draining mucosal sites produce IL-4 (29). It is intriguing to consider the possible role of IL-4 in determining the outcome of the immune response to infection. Although IL-4 has a major role in the regulation of Ig production ( 30 ), it has recently been found to have a down-regulatory effect on cell-mediated immune responses. IL-4 stimulates murine $\mathrm{T}_{\mathrm{H}} 2$ cell proliferation (31), blocks IL-2-dependent proliferation of human T cells by down-regulation of IL-2 receptor expression (32), abrogates both the IFN- $\gamma$ mediated activation of monocytes to kill Leishmania parasites (33), and blocks macrophage nitric oxide generation necessary for killing intracellular parasites (34). The cross regulatory effects of IL-4 and IFN- $\gamma$ in the host response to infection have been best demonstrated in the murine leishmaniasis model. In L. major infection, healing in C57/BL mice is accompanied by an increase in IFN- $\gamma$ production by Leishmania antigen-specific cells and in the susceptible BALB/c mice, there is an increase in IL-4 production (12-16). Injection of BALB/c mice with neutralizing anti-IL-4 antibody results in attenuation of disease in $100 \%$ and cure in $85 \%$ of the animals (15).

It is not implausible that IL-4 may play a key role in the pathogenesis of MCL lesions, perhaps by partially suppressing the antileishmanial effects of IFN- $\gamma$. Some, but not all of the parasites would be killed, resulting in the chronicity and tissue injury which characterize this form of leishmaniasis. Apparently, the local IL-4 production is insufficient to block induction of the type 1 lymphokines. The elevated Ig levels in MCL patients provide evidence for production of the type 2 lymphokines $(5,35)$. Interestingly, parallel studies of patients in Venezuela indicate that the highest levels of IL-4 mRNA occur in patients with diffuse cutaneous leishmaniasis (Dittmar et al., manuscript in preparation ). Thus IL-4 may have a key role in suppression of cell-mediated responses to infection in humans, including leishmaniasis and leprosy. Alternatively, IL-4 may have an immunopathogenic role, contributing to an autoimmune process in MCL by facilitating antibody production (36). The present data provide evidence that the pathogenesis of human leishmaniasis is associated with distinct cytokine patterns and provides a framework for studying local cytokine production in parasitic disease.

\section{Acknowledgments}

We thank Kevin Moore of DNAX for the generous gift of IL-10 primers and probe. We thank Jeffrey Ohmen and Joan Klotz for technical assistance. We are grateful to Felix Tapia, Padmini Salgame,
Barry Bloom, Jeffrey Ohmen, and Peter Sieling for insightful comments. We thank Peter Barnes for help with statistics.

This study was supported by grants from the National Institutes of Health (AI-22553 and AR-40312), the UNDP/World Bank/World Health Organization Special Program for Research and Training in Tropical Diseases (IMMLEP), and the Sasakawa Memorial Health Foundation.

\section{References}

1. Castes, M., A. Agnelli, and A. J. Rondon. 1984. Mechanisms associated with immunoregulation in human American cutaneous leishmaniasis. Clin. Exp. Immunol. 57:279-286.

2. Mendonca, S. C., S. G. Coutinho, R. R. Amendoeira, M. C. Marzochi, and C. Pirmez. 1986. Human American cutaneous leishmaniasis (Leishmania b. bra ziliensis) in Brazil: lymphoproliferative responses and influence of therapy. Clin Exp. Immunol. 64:269-276.

3. Muller, I., T. Pedrazzini, J. P. Farrell, and J. A. Louis. 1989. T-cell responses and immunity to experimental infection with Leishmania major. Annu. Rev. Immunol. 7:561-578.

4. Castes, M., A. Agnelli, O. Verde, and A. J. Rondon. 1983. Characterization of the cellular immune response in American cutaneous leishmaniasis. Clin. Immunol. Immunopathol. 27:176-186.

5. Saravia, N. G., L. Valderrama, M. Labrada, A. F. Holguin, C. Navas, G. Palma, and K. A. Weigle. 1989. The relationship of Leishmania braziliensis subspecies and immune response to disease expression in New World leishmaniasis. J. Infect. Dis. 159:725-735.

6. Pirmez, C., C. Cooper, M. Paes-Oliveira, A. Schubach, V. K. Torigian, and R. L. Modlin. 1990. Immunologic responsiveness in American cutaneous leishmaniasis lesions. J. Immunol. 145:3100-3104.

7. Paes-Oliveira, M., C. Pirmez, E. Rangel, A. Schubach, and G. Grimaldi. 1988. An outbreak of American cutaneous leishmaniasis (L. b. braziliensis) in a periurban area of Rio de Janeiro: clinical and epidemiological studies. Mem. Inst. Oswaldo Cruz Rio J. 83:427-433.

8. Chomczynski, P., and N. Sacchi. 1987. Single-step method of RNA isolation by acid guanidinium thiocyanate-phenol-chloroform extraction. Anal. Biochem. 162:156-159.

9. Yamamura, M., K. Uyemura, R. J. Deans, K. Weinberg, T. H. Rea, B. R. Bloom, and R. L. Modlin. 1991. Defining protective responses to pathogens: cytokine profiles in leprosy lesions. Science (Wash. DC). 254:277-279.

10. Yamamura, M., X.-H. Wang, J. D. Ohmen, K. Uyemura, T. H. Rea, B. R. Bloom, and R. L. Modlin. 1992. Cytokine patterns of immunologically mediated tissue damage. J. Immunol. 149:1470-1475.

11. Mosmann, T. R., H. Cherwinski, M. W. Bond, M. A. Giedlin, and R. L. Coffman. 1986. Two types of murine helper $T$ cell clones. I. Definition according to profiles of lymphokine activities and secreted proteins. J. Immunol. 136:23482357.

12. Scott, P., P. Natovitz, R. L. Coffman, E. Pearce, and A. Sher. 1988. Immunoregulation of cutaneous leishmaniasis: $T$ cell lines that transfer protective immunity or exacerbation belong to different $T$ helper subsets and respond to distinct parasite antigens. J. Exp. Med. 168:1675-1684.

13. Heinzel, F. P., M. D. Sadick, B. J. Holaday, R. L. Coffman, and R. M. Locksley. 1989. Reciprocal expression of interferon gamma or interleukin $4 \mathrm{dur}$ ing the resolution or progression of murine leishmaniasis: evidence for expansion of distinct helper T cell subsets. J. Exp. Med. 169:59-72.

14. Liew, F. Y., S. Millott, Y. Li, R. Lelchuk, W. L. Chan, and H. Ziltener 1989. Macrophage activation by interferon-gamma from host-protective $T$ cells is inhibited by interleukin (IL) 3 and IL4 produced by disease-promoting T cells in leishmaniasis. Eur. J. Immunol. 19:1227-1232.

15. Sadick, M. D., F. P. Heinzel, B. J. Holaday, R. T. Pu, R. S. Dawkins, and R. M. Locksley. 1990. Cure of murine leishmaniasis with anti-interleukin 4 monoclonal antibody: evidence for a $\mathrm{T}$ cell-dependent, interferon gamma-independent mechanism. J. Exp. Med. 171:115-127.

16. Boom, W. H., L. Liebster, A. K. Abbas, and R. G. Titus. 1990. Patterns of cytokine secretion in murine leishmaniasis: correlation with disease progression or resolution. Infect. Immun. 58:3863-3870.

17. Del Prete, G. F., M. De Carli, C. Mastromauro, R. Biagiotti, D. Macchia, P. Falagiani, M. Ricci, and S. Romagnani. 1991. Purified protein derivative of Mycobacterium tuberculosis and excretory-secretory antigen(s) of Toxocara canis expand in vitro human $\mathrm{T}$ cells with stable and opposite (type $1 \mathrm{~T}$ helper or type 2 T helper) profile of cytokine production. J. Clin. Invest. 88:346-350.

18. Haanen, J. B., R. de Waal Malefijt, P. C. Res, E. M. Kraakman, T. H. Ottenhoff, R. R. de Vries, and H. Spits. 1991. Selection of a human T helper type 1-like T cell subset by mycobacteria. J. Exp. Med. 174:583-592.

19. Modlin, R. L., F. M. Hofman, D. A. Horwitz, L. A. Husmann, S. Gillis, C. R. Taylor, and T. H. Rea. 1984. In situ identification of cells in human leprosy granulomas with monoclonal antibodies to interleukin 2 and its receptor. $J$. Immunol. 132:3085-3090. 
20. Cooper, C. L., C. Mueller, T.-A. Sinchaisri, C. Pirmez, J. Chan, G. Kaplan, S. M. M. Young, I. L. Weissman, B. R. Bloom, T. H. Rea, et al. 1989. Analysis of naturally occurring delayed-type hypersensitivity reactions in leprosy by in situ hybridization. J. Exp. Med. 169:1565-1581.

21. King, C. L., E. A. Ottesen, and T. B. Nutman. 1990. Cytokine regulation of antigen-driven immunoglobulin production in filarial parasite infections in humans. J. Clin. Invest. 85:1810-1815.

22. Limaye, A. P., J. S. Abrams, J. E. Silver, E. A. Ottensen, and T. B. Nutman. 1990. Regulation of parasite induced eosinophilia: selectively increased interleukin 5 production in helmith-infected patients. J. Exp. Med. 172:399-402.

23. Salgame, P., J. S. Abrams, C. Clayberger, H. Goldstein, J. Convit, R. L. Modlin, and B. R. Bloom. 1991. Differing lymphokine profiles of functional subsets of human CD4 and CD8 T cell clones. Science (Wash. DC). 254:279282.

24. Nathan, C. F., H. W. Murray, M. E. Wiebe, and B. Y. Rubin. 1983. Identification of interferon-gamma as the lymphokine that activates human macrophage oxidative metabolism and antimicrobial activity. J. Exp. Med. 158:670689.

25. Nacy, C. A. M. G. Fostier, M. G. Pappas, and R. R. Henry, 1983. Susceptibility of inbred mice to $L$. tropica infection: correlation of susceptibility with in vitro defective macrophage microbicidal activities. Cell. Immunol. 77:298-307.

26. Murray, H. W., B. Y. Rubin, and C. P. Rothermel. 1983. Killing of intracellular $L$. donovani by lymphokine-stimulated human mononuclear phagocytes: evidence that interferon is the activating lymphokine. J. Clin. Invest. 72:1506-1510.

27. Murray, H. W., J. J. Stern, K. Welte, B. Y. Rubin, S. M. Carriero, and C. F. Nathan. 1987. Experimental visceral leishmaniasis: production of interleukin 2 and interferon-gamma, tissue immune reaction, and response to treatment with interleukin 2 and interferon-gamma. J. Immunol. 138:2290-2297.
28. Sadick, M. D., R. M. Locksley, C. Tubbs, and H. V. Raff. 1986. Murine cutaneous leishmaniasis: resistance correlates with the capacity to generate interferon-gamma in response to Leishmania antigens in vitro. J. Immunol. 136:655661 .

29. Daynes, R. A., B. A. Araneo, T. A. Dowell, K. Huang, and D. Dudley. 1990. Regulation of murine lymphokine production in vivo. III. The lymphoid tissue microenvironment exerts regulatory influences over $\mathrm{T}$ helper cell function. J. Exp. Med. 171:979-996.

30. Finkelman, F. D., J. Holmes, I. M. Katona, J. F. Urban, M. P. Beckmann, L. S. Park, K. A. Schooley, R. L. Coffman, T. R. Mosmann, and W. E. Paul. 1990 Lymphokine control of in vivo immunoglobulin isotype selection. Annu. Rev. Immunol. 8:303-333.

31. Fernandez Botran, R., V. M. Sanders, T. R. Mosmann, and E. S. Vitetta. 1988. Lymphokine-mediated regulation of the proliferative response of clones of T helper 1 and T helper 2 cells. J. Exp. Med. 168:543-558.

32. Martinez, O. M., R. S. Gibbons, M. R. Garovoy, and F. R. Aronson. 1990 IL-4 inhibits IL-2 receptor expression and IL-2-dependent proliferation of human T cells. J. Immunol. 144:2211-2215.

33. Lehn, M., W. Y. Weiser, S. Engelhorn, S. Gillis, and H. G. Remold. 1989. IL-4 inhibits $\mathrm{H}_{2} \mathrm{O}_{2}$ production and antileishmanial capacity of human cultured monocytes mediated by IFN-gamma. J. Immunol. 143:3020-3024.

34. Liew, F. Y., and F. E. Cox. 1991. Nonspecific defence mechanism: the role of nitric oxide. Immunol. Today. 12:A17-A21.

35. Desjeux, P., F. Santoro, D. Afchain, M. Loyens, and A. Capron. 1980. Circulating immune complexes and anti-IgG antibodies in mucocutaneous leishmaniasis. Am. J. Trop. Med. Hyg. 29:195-198.

36. Avila, J. L., M. Rojas, and M. Rieber. 1984. Antibodies to laminin in American cutaneous leishmaniasis. Infect. Immun. 43:402-406. 